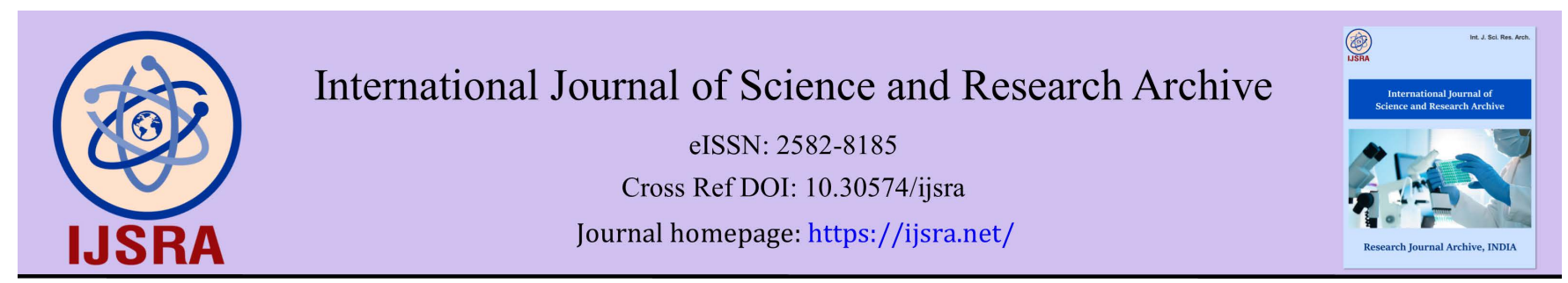

(RESEARCH ARTICLE)

\title{
Prevalence of anaemia among pregnant women attending antenatal clinic at St. Francis Referral Hospital Ifakara, Tanzania
}

\author{
Sylivester W. Mkama* \\ Department of Obstetrics and Gynaecology St. Francis University College of Health and Allied Sciences, P.O Box 175 Ifakara, \\ Tanzania.
}

International Journal of Science and Research Archive, 2021, 03(01), 041-046

Publication history: Received on 03 June 2021; revised on 13 July 2021; accepted on 15 July 2021

Article DOI: https://doi.org/10.30574/ijsra.2021.3.1.0097

\begin{abstract}
Background: Anemia in pregnancy is a worldwide public health problem affecting both developing and developed countries with significant impact on the health of mothers and fetus.

Objective: This study aimed to determine the prevalence of anemia among pregnant women attending antenatal clinic at St. Francis Referral Hospital (SFRH), Ifakara, Tanzania.

Methodology: This was a descriptive cross-sectional study conducted from January to March 2021 . A total of 116 pregnant women were enrolled in this study. Interviews were conducted followed by determination of haemoglobin level.
\end{abstract}

Results: The results revealed the prevalence of anemia among pregnant women attending antenatal clinic at SFRH to be $52.6 \%$. In this study mild anemia was $34.5 \%$, moderate anemia $13.8 \%$ and severe anemia $4.3 \%$.

Conclusion: Anemia in pregnancy is a public health problem in study setting of St. Francis Referral Hospital, Ifakara, Tanzania.

Keywords: Anemia; Pregnant women; Prevalence; Ifakara

\section{Introduction}

Anemia describes a situation in which there is a reduction of haemoglobin concentration in the blood of pregnant women to a level below $11 \mathrm{~g} / \mathrm{dl}$. Anemia is one of the most common nutritional deficiency diseases observed globally and affects more than a quarter of the world's population, especially in the developing countries [1]. Anemia is classified into mild anemia $(10-10.9 \mathrm{~g} / \mathrm{dl})$, moderate anemia $(7-9.9 \mathrm{~g} / \mathrm{dl})$ and severe anemia $(<7 \mathrm{~g} / \mathrm{dl})$. Globally, an estimated 32.4 million (38.2\%) pregnant women are anemic. Its burden was high in South East Asia (48.7\%) and Africa (46.3\%) [2]. In Africa, (57\%) of pregnant women are anemic, which corresponds to 17 million affected women, with severe consequence on health, social and economic development $[3,4]$. Studies in Africa have shown a high prevalence of anemia in pregnancy ranging from $41-83 \%$ in different settings $[5,6,7,8,9,10]$. The cause of anemia in pregnancy is multi-factorial, low caloric intake leading to deficiencies in iron, folate, Vitamin B12 and Vitamin A, as well as intestinal parasitic infections, malaria, haemoglobinopathies and HIV all have been shown to be the main causes of anemia among pregnant African women $[11,12]$.

\footnotetext{
${ }^{*}$ Corresponding author: Sylivester W. Mkama

Department of Obstetrics and Gynaecology St. Francis University College of Health and Allied Sciences, P.O Box 175 Ifakara, Tanzania.

Copyright (C) 2021 Author(s) retain the copyright of this article. This article is published under the terms of the Creative Commons Attribution Liscense 4.0.
} 
Few studies have however assessed anemia among pregnant women in Tanzania, especially in the third trimester when anemia is most likely to affect the maternal and perinatal outcomes [6,9]. Therefore, the aim of this study was to assess the prevalence of anemia among pregnant women attending antenatal clinic at St. Francis Referral Hospital, Ifakara, Tanzania. The results of this study will be used for national-level policy making and programming by concerned bodies to intervene and lessen the high burden of anemia in pregnancy.

\section{Material and methods}

\subsection{Study area}

The study was conducted among pregnant women attending routine antenatal care at St. Francis Referral Hospital, Ifakara, Tanzania. The study was conducted between January and March 2021. St. Francis Referral Hospital is in Kilombero district (Fig.1). It also serves as a referral hospital for other health facilities within Ulanga and Malinyi districts. Ifakara is located in southern central Tanzania between latitude 87'59'S and longitude 3640'59.880'. Ifakara has a population of 49532 people according to census of 2012. The main tribes are Ndamba, Pogolo and Mbunga, as well as Masai and Sukuma who migrated here as pastoralists. Main activities are farming of rice, maize, sugarcane and fishing from Kilombero river.

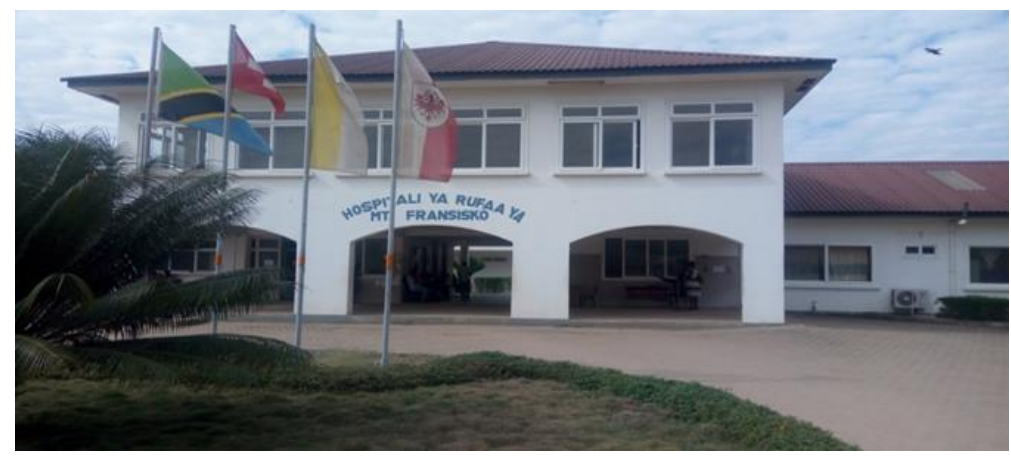

Figure 1 St. Francis Referral Hospital

\subsection{Study design}

The study design was a descriptive cross-sectional study which prevalence of anemia among pregnant women attending antenatal clinic at St. Francis Referral Hospital was studied at a time. Structured pre-tested questionnaire with key information was used to collect the desired data.

\subsection{Study population}

Women attending antenatal clinic at St. Francis Referral Hospital were involved in the study.

\subsection{Sample size}

The sample size in this study was 116 participants. The sample size calculation obtained by Kirkwood formula:

$$
N=\frac{Z a^{2} x p(1-p)}{d^{2}}
$$

\subsection{Sampling Technique}

Simple randomly technique was employed whereby participants attending at St.Francis Referral Hospital antenatal clinic were allocated numbers (even and uneven numbers). Participants who had even numbers were involved in the study.

\subsection{Data collection}

The data collected by structured guided questionnaire. The questionnaire prepared in English language and translated into Swahili to maintain the consistency and content of the questionnaire, confidentiality of information, participant's 
right and voluntarily informed consent were secured. The participants were asked the questions and their answers filled in the questionnaire by a researcher.

\subsection{Data analysis}

Questionnaires filled with irrelevant information were removed. The data from questionnaires were entered, cleaned and analysed by using Statistical Package for Social Sciences (SPSS version 20).

\subsection{Inclusion criteria}

Women attending antenatal clinic willing to participate in the study were included.

\subsection{Exclusion criteria}

Women attending antenatal clinic but unwilling to participate in the study were excluded.

\subsection{Ethical clearance}

Permission to conduct the study was obtained from research committee of St. Francis University College of Health and Allied Sciences (SFUCHAS) while permission to use participants at St. Francis Referral Hospital was obtained from the Director General of the referral hospital.

\section{Results}

Table 1 Socio-demographic characteristics of pregnant women attending antenatal clinic at SFRH

\begin{tabular}{|c|c|c|c|}
\hline Variable & Category & Frequency & Percentage (\%) \\
\hline \multirow{7}{*}{ Age (years) } & $<15$ & 3 & 2.6 \\
\hline & $15-19$ & 10 & 8.6 \\
\hline & $20-24$ & 15 & 12.9 \\
\hline & $25-29$ & 36 & 31 \\
\hline & $30-34$ & 20 & 17.2 \\
\hline & $35-39$ & 15 & 12.9 \\
\hline & $>40$ & 17 & 14.6 \\
\hline \multirow{3}{*}{ Religion } & Christian & 70 & 60.3 \\
\hline & Muslim & 40 & 34.8 \\
\hline & Pagan & 6 & 5.2 \\
\hline \multirow{3}{*}{ Marital Status } & Single & 90 & 77.6 \\
\hline & Married & 25 & 21.6 \\
\hline & Widowed & 1 & 0.9 \\
\hline \multirow{4}{*}{ Education level } & Primary & 57 & 49.1 \\
\hline & Form 4 & 40 & 34.5 \\
\hline & Form 6 & 6 & 5,2 \\
\hline & College & 13 & 11.2 \\
\hline \multirow{4}{*}{ Occupation } & Civil servants & 11 & 9.5 \\
\hline & Business & 32 & 27.6 \\
\hline & Housewife & 30 & 25.9 \\
\hline & Peasant & 43 & 37.1 \\
\hline
\end{tabular}


A total of 116 pregnant women attending antenatal clinic at SFRH were involved in this study. Age; 3(2.6\%) less than 15 years, $10(8.6 \%)$ age group 15 - 19 years, 15(12.9\%) were of age group $20-24$ years, 36(31\%) were in the age group of 25 - 29 years, 20(17.2\%) age group 30 - 34 years, 15(12.9\%) age group 35 - 39 years, and $17(14.6 \%)$ more than 40 years. Religion; Christians were 70(60.3\%), Muslim were 40(34.8\%) and Pagan were 6(5.2\%). Marital status; single 90(77.6\%), married 25(21.6\%), widowed 1(0.9\%). Education level of participants; Primary education 57(49.1\%), Form four $40(34.5 \%)$, Form six 6(5.2\%), College 13(11.2\%). Occupation of participants; civil servants 11(9.5\%), business $32(27.6 \%)$, housewife $30(25.9 \%)$ and peasants $43(37.1 \%)$ as shown in Table 1.

\subsection{Distribution of gestational age and gravidity among pregnant women attending antenatal clinic at SFRH}

In this study the gestational age of the participants was: 1-3 months were 14 (23\%), 4 -6 months were 14 (23\%), 7-9 months were 33(54\%); gravidity: primegravida were $47(77 \%)$ and multigravida were $14(23 \%)$ as shown in Table 2.

Table 2 Distribution of gestational age and gravidity among pregnant women attending antenatal clinic at SFRH

\begin{tabular}{|c|c|c|c|}
\hline Variable & Category & Frequency & Percentage (\%) \\
\hline \multirow{3}{*}{$\begin{array}{c}\text { Gestation } \\
\text { (months) }\end{array}$} & $1-3$ (First Trimester) & 14 & 23 \\
\cline { 2 - 4 } & $4-6$ (Second Trimester) & 14 & 23 \\
\hline \multirow{2}{*}{ Gravidity } & $7-9$ (Third Trimester) & 33 & 54 \\
\cline { 2 - 4 } & Primigravida & 47 & 77 \\
\hline
\end{tabular}

\subsection{Intermitent Prevention Treatment among pregnant women attending antenatal clinic at SFRH}

Pregnant women attending antenatal clinic at SFRH received the following medications: Mebendazole were 58(50\%), Ferrous sulphate were 71(61.2\%), Folic acid were 34(29.3\%), SP doses were 73(62.9\%), and Sleeping under treated bednets were $80(69 \%)$ as shown in Table 3.

Table 3 Intermitent Treatment Prevention among pregnant women attending antenatal clinic at SFRH

\begin{tabular}{|l|c|c|c|}
\hline Variables & Category & Frequency & Percentage (\%) \\
\hline Mebendazole & Yes & 58 & 50 \\
\hline Ferrous sulphate & Yes & 71 & 61.2 \\
\hline Folic acid & Yes & 34 & 29.3 \\
\hline Received SP doses & Yes & 73 & 62.9 \\
\hline Using treated bednets & Yes & 80 & 69 \\
\hline
\end{tabular}

\subsection{Distribution of haemoglobin level among pregnant women attending antenatal clinic at SFRH}

The haemoglobin distribution was studied among 116 pregnant women attending antenatal clinic at SFRH. Those who were not anemic with haemoglobin level above $11 \mathrm{~g} / \mathrm{dl}$ were 55(47.4\%), with mild anemia haemoglobin $10-11 \mathrm{~g} / \mathrm{dl}$ were $40(34.5 \%)$, with moderate anemia haemoglobin $8-9 \mathrm{~g} / \mathrm{dl}$ were $16(13.8 \%)$ and those with severe anemia haemoglobin between $4-7$ were $5(4.3 \%)$ as shown in Table 4 . Therefore, in this study the prevalence of anemia in pregnant women attending ANC at SFRH was $52.6 \%$.

Table 4 Distribution of haemoglobin level among pregnant women attending antenatal clinic at SFRH

\begin{tabular}{|c|c|c|}
\hline Variable (Hb level g/dl) & Frequency & Percentage (\%) \\
\hline $4-7$ & 5 & 4.3 \\
\hline $8-9$ & 16 & 13.8 \\
\hline $10-11$ & 40 & 34.5 \\
\hline$>11$ & 55 & 47.4 \\
\hline Total & 116 & 100 \\
\hline
\end{tabular}




\section{Discussion}

Anemia in pregnancy is one of the most widespread public health problems especially in developing countries and has significant health, social and economic consequences.

The results in this study showed that prevalence of anemia in pregnant women attending antenatal clinic at SFRH was $52.6 \%$. The prevalence of anemia in our study was higher compared to a study done in northern Tanzania which showed prevalence of $47.4 \%$ as reported by [13]. The prevalence in this study is higher than that reported elsewhere [14]. A study done in Kenya showed prevalence of $40.7 \%$, while a study done in northwestern Ethiopia revealed prevalence of $36.1 \%$ [15]. Only five participants (4.3\%) with severe anemia were detected in the present study while those found to be anemic were mild and moderate anemia at $34,8 \%$ and $138 \%$ respectively. This indicates that may be there is less improvement in maternal nutrition in this study area. Over the years, the government of Tanzania has been strengthening the antenatal care services and every pregnant woman is given iron supplementation to combat anemia, deworming, malaria prophylaxis and treated mosquito nets [16]. Women who had secondary or higher education were less likely to be anemic compared to their counterparts. Education has been reported to reduce the risk of being anemic in several studies. Educated pregnant women have better income and eat nutritious food and hence do not get nutritional anemia [17]. A study done in Ethiopia also reported higher prevalence of anemia among pregnant women who had no education [18].

Poor income leads to limited access to nutritious foods and is associated with poor eating habits that might lead to anemia. A study done in Ethiopia showed that women with low income were more anemic than women with higher income [19].

This study found that $23 \%$ of pregnant mothers initiated antenatal care in the first trimester and 23\% and 54\% in their second and third trimester respectively. This study is in line with the study done in Kenya which concluded that during the first trimester pregnant women do not attend antenatal clinic hence there being low attendance of antenatal care $[14]$.

This study shows that pregnant women attending antenatal clinic with an age $>40$ years were (14.6\%). This agrees with previous study which reports that as maternal age increases, the mother may face repetitive pregnancies, the result of labor related complications the mother can be subjected to other illnesses which may predispose her to anemia [20].

This study highlights the prevalence of anemia to be significantly higher among pregnant women attending antenatal clinic at SFRH.

\section{Conclusion}

In this study, the prevalence of anemia among pregnant women attending ANC at SFRH was 52.6\%, the majority of the participants had moderate type of anemia (Haemoglobin $10-11 \mathrm{~g} / \mathrm{dl}$ ). The observed prevalence of anemia might affect the birth outcome of pregnant women. It is recommended that the ongoing interventions including health, nutrition and dietary education about anemia should be given top priority.

\section{Compliance with ethical standards}

\section{Acknowledgments}

I wish to express my appreciation to the Management of St. Francis University College of Health and Allied Sciences, Antenatal Clinic staffs and the Director General of St. Francis Referral Hospital for their support in this study. The study was funded by St. Francis University College of Health and Allied Sciences, Ifakara, Tanzania.

\section{Statement of informed consent}

Written informed consent was obtained from all antenatal mothers who consented to the study, records were coded and participants/ Researcher names were not used. All the information collected remained confidential and was used for purposes of the study only. Participation was voluntary and no incentives were given. 


\section{References}

[1] de Benoist B, Mclean E, Egli I, Cogswell M. Worldwide prevalence of anemia 1993-2005: WHO Global Database on Anemia: World Health Organization. 2008.

[2] WHO. The global prevalence of anemia in 2011.World Health Organization, Geneva, Switzerland. 2015.

[3] Levin HM. A benefit-cost analysis of nutritional programs for anemia reduction. Research Observer. 1986; 2: 219 245.

[4] Allen LH. Anemia and iron deficiency: effects on pregnancy outcome. American Journal of Clinical Nutrition. 2000; 71(Suppl): 1280S-1284S.

[5] Meda N, Mandelbrot L, Cartoux M, Dao B, Ouangre A, Dabism F. Anemia during pregnancy in Burkina Faso, West Africa, 1995-1996: prevalence and associated factors. Bulletin of the World Health Organization. 1999; 77: 916922.

[6] Kidanto HI, Morgen L, Lindmark G, Massawe S, Nystrom L. Risk for pre-term delivery and low birth weight are independently increased by severity of maternal anemia, South African Medical Journal. 2009; 99: 98-102.

[7] Uneke CJ, Duhliska DD, Igbinedion EB. Prevalence and public health significance of HIV infection and anemia among pregnant women attending antenatal clinics in south-eastern Nigeria. Journal of Health Population and Nutrition. 2007; 25: 328-35.

[8] TDHS. Tanzania Demographic and Health Survey 2004-2005. Dar es Salaam, Tanzaania: Naational Bureau of Statistics and ORC Macro. 2005.

[9] Haggaz AD, Radi EA, Adam I. Anemia and low birth weight in Western Sudan. Transactions of the Royal Society of Tropical Medicine and Hygiene. 2010; 104: 234-36.

[10] Msolla MJ, Kinabo JL. Prevalence of anemia in pregnant women during the last trimester. International Journal of Food Science and Nutrition. 1997; 48: 265-70.

[11] Antelman G, Msamanga G, Spiegelman D, Urassa EJ, Narh R, Hunter D, Fawzi W. Nutritional factors and infectious disease contribute to anemia among pregnant women with Human Immunodeficiency Virus in Tanzania, Journal of Nutrition. 2000; 130: 1950-1957.

[12] Verhoeff FH, Brabin BJ, Chimsuku L, Kazembe P, Broadhead RL. An analysis of the determinants of anemia in pregnant women in rural Malawi a basis for action. Annals of Tropical Medicine and Parasitology. 1999; 93: 11933.

[13] Msuya SE, Hussein TH, Uriyo J, Sam NE, Stray-Pedersen B. Anemia among pregnant women in northern Tanzania: prevalence, risk factors and effect on perinatal outcomes, Tanzania Journal of Health Research. 2011; 13(1): 3339.

[14] Ndegwa SK. Anemia \& Its Associated Factors Among Pregnant Women Attending Antenatal Clinic At Mbagathi County Hospital, Nairobi Count, Kenya, African Journal of Health Sciences. 2019; 33(1): 59-72.

[15] Melku M, Agmas A. Maternal anemia during pregnancy in Bahrdar Town, Northwestern Ethiopia. A facility-based retrospective study, Applied Medical Research. 2015.

[16] Afnan-Holmes H, Magoma M, John T. Tanzania's countdown to 2015: An analysis of two decades of progress and gaps for reproductive, maternal, newborn and child health, to inform priorities for post 2015, The Lancet Global Health. 2015; 3(7): 396-409.

[17] Bureau of Statistics (NBS) Tanzania and ICF Macro (2011). Tanzania Demographic and Health Survey 2010, NBS and ICF Macro Dar es Salaam, Tanzania.

[18] Melku M, Addis Z, Alem M, Enawggaw B. Prevalence and predictors of maternal anemia during pregnancy in Gondar, Northwest Ethiopia: an Institutional based cross-sectional study, Anemia. 2014; 9.

[19] Bekele A, Tilahun M, Mekuria A. Prevalence of anemia and its associated factors among pregnant women attending antenatal care in Health Institutions of Arba Minch Town, Gamo Gofa Zone, Ethiopia: A cross-sectional study, Anemia. 2016; Article ID 1073192.

[20] Lin V. Prevalence, risk factors and associated adverse pregnancy outcomes of anemia in Chinese pregnant women: a multicentre retrospective study, BMC Pregnancy and Childbirth. 2018; 18: 111. 